http://dx.doi.org/10.23925/2176-2767.2019v64p82-114

Recebido: 30/11/2018

Aprovado: 22/02/2019

\title{
ARTIGO
}

\section{OS AMERICANISMOS NAS PÁGINAS DA REVISTA DE DERECHO HISTÓRIA Y LETRAS E DA REVISTA AMERICANA}

\section{AMERICANISMS IN THE PAGES OF REVISTA DE DERECHO HISTÓRIA Y LETRAS AND REVISTA AMERICANA}

\author{
FERNANDO VALE CASTRO*
}

\section{RESUMO}

O objetivo deste artigo é realizar uma análise acerca de algumas das concepções de Americanismo presentes na Revista de Derecho Historia y Letras de Buenos Aires, periódico que circulou entre 1898 e 1924, fundado e dirigido pelo diplomata, intelectual e político argentino Estanislao Severo Zeballos e na Revista Americana editada no Rio de Janeiro de 1909 a 1919, publicada pelo Ministério das Relações Exteriores do Brasil e que teve o Barão do Rio Branco como seu grande incentivador.

Palavras-chave: Americanismo; Revista de Derecho Historia y Letras; Revista Americana

\begin{abstract}
The aim of this article is to analyze some conceptions about Americanism presents in the Revista de Derecho Historia y Letras of Buenos Aires, a periodical that circulated between 1898 and 1924, founded and directed by Argentine diplomat, intellectual and political Estanislao Severo Zeballos and the Revista Americana published in Rio de Janeiro, between 1909 and 1919, printed by the Foreign Affairs of Brazil and which had the Barão do Rio Branco as its great encouraging.
\end{abstract}

Keywords: Americanism; Revista de Derecho Historia y Letras; Revista Americana 


\section{Introdução}

Ao se observar uma revista como local no qual se realiza uma prática social de produção de sentido sobre a experiência coletiva, torna-se fundamental observar a questão da produção do discurso. Para uma melhor análise dos textos me aproximo de alguns pressupostos da chamada "virada linguística". ${ }^{1}$ Nesta perspectiva é fundamental recuperar a identidade histórica das obras intelectuais, por meio de uma metodologia histórica e intertextual, ou seja, que apresenta como objetivo alcançar o sentido do texto em seu tempo, afastando-se, portanto, de possíveis visões anacrônicas e reducionistas. Perceber o texto inserido no seu contexto reconstrói sua historicidade, ao mesmo tempo em que lhe atribui o caráter de ação. Nesse sentido é sobre a ideia de discurso e não sobre a individualidade dos autores, que a abordagem se baseia.

Buscando sintetizar essa proposta metodológica, estou considerando os articulistas das revistas como enunciadores de atos de fala em resposta a determinadas questões em discussão no período e que contribuíram para a criação de uma determinada "comunidade argumentativa", elaborando e emitindo "lances"² específicos. Para se compreender tal construção, cabe investigar, na medida do possível, a historicidade da sua produção associada à intencionalidade da sua escrita.

De acordo com Regina Crespo $^{3}$ desde fins do século XIX a criação e circulação de revistas na e sobre a América Latina representaram "um espaço privilegiado para o estabelecimento de pautas de discussão e ação não apenas no campo cultural e intelectual, mas também no âmbito sócio político". ${ }^{4}$ Os periódicos se caracterizam como um locus no qual seus articulistas podem expressar suas concepções acerca de uma série de temáticas caras ao 
cenário político e cultural de sua época. Neste sentido, para Crespo, o processo de compreender como são estabelecidos, difundidos, modificados, adaptados e até mesmo substituídos, os cânones ideológicos e culturais, tanto em nível regional quanto em nível nacional e continental, passa, inevitavelmente, pela análise desse tipo de publicação, responsável pela difusão e debate de ideias no continente.

Antes da análise das revistas faz-se necessário apresentar, ainda que muito brevemente, alguns aspectos que marcaram o período no qual os periódicos circularam.

\section{A América do Sul em fins do século XIX e início do XX}

A época na qual as revistas circularam caracterizou-se por uma perspectiva de mudança em consequência das transformações ocorridas no seio do mundo capitalista. Nas artes, na técnica, nas ciências, nas relações de trabalho observava-se a aceleração do tempo e a diminuição das distâncias. Passou-se a viver um efetivo crescimento na base geográfica da produção, fato que reforçou a lógica da Divisão Internacional do Trabalho, em perfeita sintonia com os avanços imperialistas de dividir o mundo em grandes áreas de influências e de possessões coloniais. Essas transformações estiveram diretamente ligadas ao extremo avanço tecnológico marcado, entre outros, pelo telefone, o telégrafo sem fio, o fonógrafo, o cinematógrafo, ferrovias que cortavam a Europa e os EUA, automóveis, etc, bem como ao grande desenvolvimento na área médica que representou um aumento claro na expectativa de vida. Nesse sentido, é possível afirmar que surgia uma nova era que mexeu no imaginário popular de forma inequívoca causando forte 
impacto nas pessoas, especialmente as do mundo desenvolvido e industrial, que passaram a viver um tempo de prosperidade que só seria perdido após $1914 .^{5}$

A intelectualidade sul-americana não ficou imune a tais transformações. A virada do século XIX para o século XX é extremamente fecunda para se observar profundas mudanças nos campos político e cultural, fato que faz a época ser uma das mais privilegiadas pela historiografia nas análises acerca dos inúmeros projetos desenvolvidos pela intelectualidade continental. ${ }^{6}$ A partir do último quartel do Oitocentos houve o surgimento de vários grupos de intelectuais, preocupados em construir novas identidades e projetos de nação em várias partes do continente.

Tais projetos, fundamentalmente, baseavam-se na assimilação e difusão de idéias evolucionistas e cientificistas com o objetivo de levar as nações do continente ao mais alto nível de civilização, procurando universalizar os problemas nacionais. Essa geração ${ }^{7}$ valeu-se da ciência moderna, entendida como norteadora da administração pública e base para alcançar o progresso, fato que fortaleceria a crença de que sem a presença dos intelectuais a sociedade dificilmente se beneficiaria das conquistas alcançadas.

A intelectualidade do continente se esforçou em explicar as razões do atraso e em procurar formas de superá-lo. Como o objetivo principal seria entrar no círculo da modernidade, as elites e os intelectuais procuraram construir imagens das suas nações que ora se diferenciassem, ora se aproximassem, das demais repúblicas sul-americanas ao mesmo tempo em que procuravam a gênese das respectivas nacionalidades. Em 
última análise a intelectualidade desse período desejava inscrever suas ideias na tradição do progresso e da civilização, herdadas do Iluminismo, buscando criar um saber próprio sobre a América Ibérica.

Tal pensamento, apesar das peculiaridades nacionais e regionais, apresentava problemas similares que desafiavam os intelectuais do período a elaborar diagnósticos e prognósticos para o Continente a partir das mesmas fontes teóricas e com o objetivo de construir, nas suas respectivas nações, uma sociedade "civilizada", "moderna" e "progressista". Este cenário de profundas transformações caracterizadas pela significativa urbanização de cidades como Rio de Janeiro, Buenos Aires, Santiago do Chile, Montividéu, etc, associado a um processo de industrialização e a um crescimento demográfico com o aumento das camadas médias e da classe operária, trouxe consigo uma profusão de debates que, em síntese, refletiam sobre projetos para a superação do "atraso" de suas nações e, consequentemente, do "Continente" sulamericano.

Neste contexto um dos grupos que mais se destacou na formulação de propostas para se pensar o continente foi o dos diplomatas que passaram a estabelecer projetos nacionais que deveriam se inserir em uma lógica continental. Logo, essa geração de intelectuais, com inserção nas fileiras diplomáticas sul-americanas, passou a articular estratégias de cooperação entre vizinhos. Nesse sentido, tanto a Revista de Derecho Historia y Letras quanto a Revista Americana podem ser pensadas como um espaço de reflexão do continente.

$\mathrm{Na}$ Argentina, partir de fins dos anos 1880, estabeleceu-se um novo contexto institucional com características que perduraram até as 
primeiras décadas do século XX. Os triunfos militares auxiliaram no processo de consolidação de um centro de poder forte, cujas bases jurídicas estavam na Constituição de 1853 e que deviam consolidar "uma

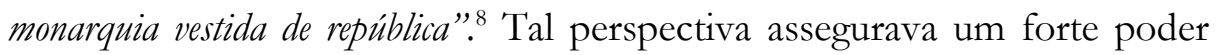
presidencial, exercido de maneira ilimitada ao longo de todo o território nacional que fortalecia a possibilidade de intervenção nas Províncias. Por outro lado, os controles institucionais do Congresso, sobretudo o estabelecimento do fim da reeleição, garantiam que o Poder Executivo não se transformasse em uma tirania.

A historiografia ${ }^{9}$ consagra que esse mecanismo foi idealizado por conta das sucessivas guerras civis e a facilidade com que as elites se dividiam. Convém salientar que nas últimas décadas do século XIX e primeiras do XX, o Poder Executivo valeu-se dessas premissas para disciplinar os grupos provinciais através de uma estratégia que oferecia certa autonomia na decisão de assuntos locais.

Em síntese, a época caracterizou-se como sendo de significativa prosperidade em um contexto baseado em acordos nos quais tanto as elites quanto os segmentos mais pobres do interior argentino tiveram oportunidade de usufruir os respectivos ganhos materiais, fato que explicaria o apoio à nova ordem política estabelecida a partir de Buenos Aires. Tal cenário possibilitou que uma nova estratégia diplomática fosse elaborada com o objetivo de estabelecer novos paradigmas para a política externa da nação. ${ }^{10}$

$\mathrm{Na}$ virada para século XX a intelectualidade argentina passou a olhar com mais atenção para seus "vizinhos". Os projetos de futuro elaborados teriam que dar conta de uma nova realidade que, 
indubitavelmente, por conta das mudanças ocorridas no período, aproximava a Argentina do restante do continente sul-americano. Por conseguinte, nesse período, houve um evidente fortalecimento de um pensamento americanista, apropriado, a partir de então, por uma perspectiva panamericanista que deveria marcar uma aproximação com o intuito de garantir uma cooperação entre as nações da América do Sul.

Nesta mesma época, observa-se, no Brasil, o surgimento da chamada geração de $1870,{ }^{11}$ considerada, por muitos autores, a primeira a pensar um projeto modernizador para o país. Essa geração de intelectuais brasileiros da virada do século XIX para o XX, independente das interpretações diversas, que conseqüentemente levavam à disputa entre os vários grupos intelectuais formados, tinha um ponto em comum, o de pensar a realidade brasileira como parte integrante do concerto cultural estrangeiro, vinculando o Brasil a esse projeto civilizador que possibilitaria, conforme dito, uma integração continental, considerada bastante possível, na medida em que havia sido proclamada a República brasileira em 1889, fato que havia derrubado o principal obstáculo para a integração entre o Brasil e os demais países da América do Sul ao longo do século XIX.

Ideias que defendiam a construção de uma cooperação continental na América não eram uma novidade, podendo ser observadas desde os primeiros anos após as independências se for considerada a iniciativa de Simon Bolívar de, em 1824, convocar os países do continente para um Congresso no Panamá, - reunido em 1826 - no qual se debatiam mecanismos de cooperação entre as recém formadas nações americanas e que "sirviese de consejo en los grandes conflictos, de punto de contacto en los peligros 
comunes, de fiel intérprete en los tratados públicos cuando ocurrieran dificultades y de conciliador en las diferencias entre los pueblos". ${ }^{12}$ O Congresso contou com a participação da Colômbia, Venezuela, Equador, Chile, Argentina, Peru, México e América Central. Ao longo do século XIX, tal premissa permeou alguns dos debates e ações em torno da construção de projetos de identidades continentais. ${ }^{13}$

Em uma perspectiva sul-americana, no fim do século XIX e primeiras décadas do XX, de um modo geral, a noção de uma união americana foi apropriada como um dos principais pilares da diplomacia continental, configurando-se em um instrumento de defesa da soberania e da igualdade jurídica dos Estados, que deveria se constituir nos princípios legitimadores das relações internacionais do continente. Entretanto, convém observar a presença de certa dicotomia entre a prática e a teoria política internacional, uma vez que, por um lado, havia a retórica da solidariedade hemisférica e da consequente igualdade entre soberanias, enquanto, em termos práticos, ocorriam sucessivas intervenções dos Estados Unidos em diferentes nações, sobretudo, na América Central e no Caribe. Do ponto de vista prático, a cooperação continental ficou praticamente restrita às formulações teóricas. Tal fato se explica, para além de certa desconfiança em relação aos reais interesses da política externa estadunidense, pelo ambiente de rivalidade regional que marcava as relações entre as repúblicas sul-americanas. ${ }^{14}$

É possível observar que na América do Sul existia um contexto de rivalidades geopolíticas, com disputas territoriais, corrida armamentista, tendência à formação de alianças e contra-alianças. ${ }^{15} \mathrm{~A}$ formação de blocos regionais era uma preocupação constante das Chancelarias do 
continente, na medida em que havia um sentimento, até certo ponto comum, de se bloquear, em especial no mundo hispano-americano, as intervenções estadunidenses, configurando, tais uniões, em elementos aglutinadores para uma resistência continental. Porém, os vários problemas fronteiriços prejudicavam a possibilidade de uma unidade política da região, pois, na prática, a aproximação de dois Estados estimulava a formação de um bloco contrário, como profilaxia à uma possível ruptura do equilíbrio político. ${ }^{16}$

Em um cenário que se mostrava cada vez mais tenso e belicoso pode-se destacar que várias iniciativas foram elaboradas no sentido de se estabelecer mecanismos de aproximação que possibilitassem as nações do continente conhecer melhor o "outro" como forma de atenuar as tensões presentes à época. Penso as Revistas inserindo-as nessa lógica de criação de estratégias que visavam estabelecer uma maior aproximação entre as nações sul-americanas.

\section{A Revista de Derecho Historia y Letras}

A Revista de Derecho Historia y Letras durante mais de um quarto de século notabilizou-se como um espaço privilegiado de construção de conhecimento elaborando diagnósticos e prognósticos acerca de uma série de temas considerados relevantes no período. Observando alguns números do periódico foi possível perceber uma significativa quantidade de artigos versando sobre a Argentina com ênfase nos vários aspectos da sua história, economia, política, relações sociais, cultura e política externa. As histórias de outros países da América Latina, especialmente da 
América do Sul, também eram valorizadas. Outrossim, artigos jurídicos principalmente sobre Direito Civil, Constitucional e Internacional, língua e literatura latino-americana, arte, folclore, biografias de nomes relevantes da política nacional e internacional, trajetórias de intelectuais, teatro, religião, educação, conflitos e conferências internacionais, economia, panamericanismo etc.

Descrevendo a Revista ela se dividiu nos seus mais de 25 anos de circulação em 76 tomos. Editada mensalmente a cada quatro números um tomo era formado, totalizando três tomos anuais. Cada número girava em torno de 150 páginas com pequenas oscilações ao longo do período. A sua impressão esteve até 1913 a cargo da Imprenta Litografia $y$ Encuadernación de Jacob Peuser. Nos dois anos seguintes foi publicada pelos Talleres Gráficos Duílio Sorrentino. Em 1915, nova troca para a Imprenta Suiza e posteriormente para os Talleres Gráficos L.J. Rosso y Cis. Por fim, a partir de maio de 1919 até o último número publicado a empresa responsável foi a Talleres Gráficos de Schenone Hnos y Linari. Em uma contagem aproximada a Revista apresenta algo em torno de 45 mil páginas.

$\mathrm{Na}$ apresentação do primeiro número Zeballos $^{17}$ salienta o que deveria ser o objetivo central, o propósito da publicação:

"Las instituciones pierden terreno aunque lo ganen los progresos materiales. Los héroes del desgobierno y de la licencia social alimentan el egoísmo generado por la abundancia o por las facilidades económicas. El carácter de los hombres se debilita y aparece la indiferencia cívica, cediendo a los elementos inferiores y parasitarios la suerte y el gobierno común.

Lo han demostrado escritores notables y lo advierten los grupos dirigentes de la República Argentina y el Nuevo Mundo; pero sus fuerzas están desalojadas o dispersas. La Revista nace destos anhelos sociales[...] 
La acción de la Revista será en materia de Derecho, critica y científica, a vigorizar las nociones del Derecho y del Deber en el hogar, en la educación, en las asambleas legisladoras, en la administración de justicia, en el funcionamiento administrativo y en el ejercicio de las libertades políticas y civiles en las naciones latinoamericanas y de una manera especial y directa en la Republica Argentina.

Los estudios históricos están incorporados a las grandes escuelas, su enseñanza es virtud fundadora. La Revista se ocupará pues de los hechos pasados en su relación con el desenvolvimiento orgánico de la sociedad. La crónica tiene para sus páginas un interés secundario, pero felizmente empieza para la literatura histórica en la República y en América el período de la critica y de la filosofía.

No será extraño a este plan lo estímulo de la cultura literaria. Los países nuevos formados por la combinación de los elementos propios con las tendencias, el capital y los brazos extranjeros, no pueden abandonar sus orígenes en su marcha e influencias eventuales. Es necesario encauzarlos y defenderse de la vulgaridad utilitaria persiguiendo un ideal en el Arte. Consideramos por eso un deber y un honor ofrecer estas páginas a todos los espíritus selectos que contribuyan a la civilización argentina y americana con un brillante y severa difusión de las letras". ${ }^{18}$

O título do periódico explicita o que viria a ser uma das marcas da Revista: a presença constante, em praticamente todos os seus artigos, dos três temas considerados por Zeballos, como os grandes pilares da publicação, o Direito, a História e as Letras, na medida em que deveriam ser esses os grandes eixos reflexivos da intelectualidade continental.

Nos artigos que versam sobre o Direito observa-se que praticamente todas as áreas eram contempladas com especial destaque para o Direito Internacional Público e Privado, bem como o Direito 
Comercial. É possível pensar que a Revista apresentava como preocupações centrais tanto a compreensão do desenvolvimento da Ciência Jurídica na Argentina quanto a elaboração de uma análise em perspectiva comparada, na medida em que eram bastante comuns os artigos sobre questões jurídicas de outras nações, tais como: Brasil; Chile; Estados Unidos; Bélgica; Rússia etc. Paralelo a essas questões mais amplas, o periódico caracterizou-se também como um espaço de divulgação das Conferências da International Law Association.

No campo da História é possível afirmar que a Revista aparentemente assumia uma posição de valorizar aspectos da formação argentina com destaque para a política, cultura e identidades nacionais através tanto de artigos quanto de compilações de documentos históricos. Destaco também a presença de artigos com questões relevantes para a época como, por exemplo: a Guerra Russo-Japonesa; a imigração em massa; doutrinas sociais como o comunismo e o socialismo; ascensão norte-americana; Primeira Guerra Mundial, etc., além de textos referentes à formação histórica das várias nações latino-americanas, com especial destaque para as sul-americanas, que, muitas vezes, destacavam datas comemorativas.

As Letras foram valorizadas no periódico por meio de uma dupla estratégia, a saber: artigos sobre temas literários argentinos e estrangeiros com ênfase tanto na prosa quanto na poesia, enfatizando-se autores e temáticas consideradas relevantes e um espaço privilegiado para a tradução de autores clássicos. Igualmente, vale ressaltar a presença de algumas seções como a denominada Anacleta que se caracterizava como uma espécie de compendio das atividades culturais e comentários de 
conferencias realizadas na Argentina e no estrangeiro, bem como um espaço para a realização de comentários de livros e artigos argentinos, americanos e europeus.

Dentro da perspectiva de pensar a Revista de Derecho Historia y Letras como um espaço no qual ocorriam debates que permitem notar um processo de elaboração de construções discursivas acerca de temáticas ricas para aquele momento histórico e que refletiam interesse em um possível processo de aproximação entre as nações do continente, ganhou destaque nas páginas do periódico a discussão sobre americanismo que consistia, à época, na integração entre os países da América. Entretanto, há, pelo menos, duas perspectivas diferentes em relação a esses processos de integração: uma, que pode ser pensada por um viés sul-americano, denominada bolivarismo; e outra, capitaneada pelos Estados Unidos que era conceituada como monroísmo. Na Revista de Derecho, História y Letras pode ser percebida a defesa das duas interpretações do americanismo, com a elaboração tanto de críticas quanto de defesas à postura assumida pelos Estados Unidos no continente americano.

No artigo Solidariedade latino-americana ${ }^{19}$ o ministro do Supremo Tribunal Argentino, Adolfo Sánchez, defendia a cooperação entre os países da América do Sul como forma de impedir ações imperialistas na região. A união não deveria levar em conta interesses individuais, mas o benefício mútuo através de uma aliança defensiva. O autor destaca que homens como Simón Bolívar, Bernardo Monteagudo e Sáenz Peña tentaram realizar integrações, mas a base de suas ações era militar. Para Sánchez a forma mais eficaz de defesa seria a cooperação diplomática, ideia largamente difundida num período marcado pela grande atuação 
intelectual de diplomatas, na qual se destacavam Rio Branco, no Brasil, e Zeballos, na Argentina.

Para que a aliança prosperasse era importante a não intervenção de potências estrangeiras em assuntos da América do Sul. A principal preocupação era com os Estados Unidos que estavam estendendo sua influência na região. Para conter essas ações seria importante que os países manifestassem sua opinião frente à potência:

Es necesario y conveniente manifestarnos en forma elocuente y viril a los Estados Unidos, que no estamos dispuestos á admitir su tutoría imperialista y deprimente de nuestras naciones civilizadas, dignas de ser respetadas por ellos como lo son por todas potencias más cultas de Europa". ${ }^{20}$

A resistência estadunidense vinha sendo o principal empecilho para o desenvolvimento da diplomacia e da arbitragem entre os países da América do Sul, já que se entendia que qualquer solidariedade latina e/ou sul-americana deveria estar sujeita às demandas de Washington. Assim, a única forma de promover a união desejada por Sánchez seria impedindo a participação dos Estados Unidos.

No necesitamos, pues, de la colaboración yanqui para resolver el problema de nuestra solidariedad, por las razones apuntadas y porque en cada una de estas naciones latinas existe pléyade de hombres eminentes y patriotas para consumar la obra más perfecta, provechosa y fecunda en pro de nuestra estabilidad y civilización. $^{21}$

O chileno Vicuña Subercasseaux ${ }^{22}$ é outro que, nas páginas da Revista, defende a integração entre os países da América do Sul sem a 
interferência estadunidense. A principal questão colocada em seu artigo El congresso pan-americano de Rio foi se a América do Sul precisava dos Estados Unidos? Para ele este país estaria construindo um protetorado no continente justificando suas ações a partir de sua doutrina de cooperação, denominado de panamericanismo.

Em 1906 o secretário de Estado norte-americano Elihu Root publicou na Revista o artigo El verdadero objecto de La unidad pan americana, ${ }^{23}$ no qual resumia o discurso do senador John W. Daniel, que defendia ações que colaborasse para a consolidação do pan-americanismo, que seria uma forma de integrar os Estados Unidos aos demais países do continente.

A principal ideia defendida por Daniel era que os Estados Unidos deveriam estabelecer uma maior influência entre os países da América, o que consequentemente diminuiria a influência européia sobre o continente. O senador é um defensor da Doutrina Monroe e crê no estreitamento de relações entre o seu país e os vizinhos, diminuindo a distância que haveria entre eles.

Asi es que, al asumir nuestra actitud política, que tiene por objecto advertirle á Europa, com arreglo á doctrina de Monroe, que se aparte del território de Centro y Sur América, aparecemos como relativamente extraños para dichas Repúblicas, em tanto que Europa tiene com ellas relaciones directas. ${ }^{24}$

A partir da leitura do artigo Importancia de la Conferencia Panamericana de Rio de Janeiro, ${ }^{25}$ em que estão transcritos discursos de importantes diplomatas do período, como Joaquín D Casasús, embaixador do México; Joaquim Nabuco, embaixador do Brasil; Joaquín Calvo, ministro da Costa 
Rica e Ignácio Calderón, embaixador da Bolívia, pode-se perceber que a postura da maioria dos gabinetes de relações exteriores dos países da América Ibérica, naquele período, era favorável ao modelo de panamericanismo liderado pelos Estados Unidos.

Para Joaquin Casasús as ações do pan-americanismo promoveriam a união entre as nações do continente de forma pacífica. Ele ressalta a importância dos Estados Unidos no processo de trocas mútuas, que permitiriam o desenvolvimento do continente. O país teria um papel fundamental no movimento civilizador ao levar ao mundo seus ideais de liberdade e suas instituições democráticas. Tal missão reforça a idéia da necessidade da cooperação entre os países visando seu desenvolvimento.

La América no podría apartarse de este movimiento civilizador, u los Estados Unidos en el siglo XVIII habían enseñado al mondo cómo era posible que los pueblos viviesen y prosperasen gobernándose por si mismos, bajo La egida de instituciones libres, querían a la vez demonstrar que no era vano el intento de procurar que los pueblos del Continente, sin daño para su riqueza y sin menoscabo de su independencia, se acercaran los unos á los otros para conocer mejor sus necesidades comerciales, y unificar su legislación en todo aquello que no perjudicará á sus primordiales intereses. ${ }^{26}$

A análise dessa pequena mostra de artigos sobre o conceito de Americanismo, mesmo estando longe de esgotar a temática, permitiu um interessante exercício de leitura no qual é possível observar que a Revista de Derecho, Historia y Letras constituiu-se em um fórum privilegiado de debates sobre os possíveis caminhos que poderiam ser trilhados pelas nações sul-americanas. Outrossim, permite observar o periódico em 
questão como um objeto rico para se analisar determinados aspectos da História Intelectual argentina e do continente nos primeiros anos do século XX.

\section{A Revista Americana}

De acordo com Álvaro da Costa Franco, ${ }^{27}$ Diretor do Centro de História e Documentação do Itamaraty, a Revista Americana surgiu como um projeto inovador de cooperação intelectual internacional desempenhando, durante dez anos, "papel de grande relevância, e único, em nosso cenário cultural”, sendo núcleo de cooperação entre intelectuais americanos. Esta cooperação teria funcionado, segundo Costa Franco, como alicerce da política de aproximação com os "vizinhos" do Brasil.

O editorial do primeiro número afirmava que Revista tinha como objetivo:

"Divulgar as diversas manifestações espirituais da América e seguir ao mesmo passo, paralelamente, o traçado superior da sua evolução política e econômica, tornando-se um traço de união entre as figuras representativas da intelectualidade desta parte do mundo.

Ela facilitará ao historiador e ao geógrafo, ao político e ao jornalista, ao artista e ao filósofo, elementos seguros determinantes de uma noção exata e precisa dos múltiplos e paradoxos, aspectos da nossa vida espiritual". 28

A Revista Americana é considerada como um dos instrumentos da política americanista do Barão do Rio Branco. ${ }^{29}$ Esta política insere-se em 
um novo momento da política externa brasileira, inaugurado com a Proclamação da República.

No já citado editorial do primeiro número da Revista, era constatado o hiato cultural existente entre as Américas, "continente conbecido aos fragmentos" que levava a "ignorância intelectual" entre os países do continente. Tal fato reforçava-se pelas distâncias que separam os países americanos assim como pela ausência, quase absoluta, de meios de comunicação rápidos e eficientes.

Havia a necessidade de se criar uma identidade própria para o Brasil e a América, na medida em que:

“... as ideias, para serem aceitáveis, necessitam trazer a
marca européia e transpor os mares nos bojos dos
transatlânticos, o descaso injustificável pelas coisas do
nosso continente; a indiferença pela sua história; o
desamor às suas tradições; o desprezo pelos
incontáveis aspectos de sua natureza e ter - se -á um
quadro quase completo de várias causas por que as
gentes americanas se desconhecem voluntariamente.
$[\ldots .$.
Quando os povos americanos tiverem uma noção mais
exata do valor das suas fortes qualidades originarias e
nativas, ainda não de todo esmaecidos ao influxo das
culturas exóticas; quando reconhecerem que o nosso
continente, tão mal conhecido e ultrajado, constitui,
por si só, uma matriz perene de estudos, exames,
indagações...”

A Revista Americana era um periódico mensal, impresso pela Imprensa Nacional, tendo circulado de maneira contínua de outubro de 1909 a setembro de 1910. Após intervalo de três meses, reapareceu em janeiro de 1911, inaugurando o segundo ano do periódico. Editado em brochura se estruturava em um formato de pequenas dimensões 
(aproximadamente $16 \mathrm{~cm}$ por $29 \mathrm{~cm}$ ), porém quase sempre volumoso (as menores edições superando 150 páginas e as maiores 300 páginas). A capa impressa em papel pardo apresentava um cabeçalho com a identificação do ano e número do volume e do mês de circulação, um sumário com a indicação dos autores e respectivos artigos e de outras seções: notas, redação, cartas.

Fogem à essa regra os quatros números editados em 1915, nas quais a Revista como "Publicação Quinz̧enal de Sciencias e Artes", apresentou artigos como uma perspectiva mais artística, assim como lançou o "Suplemento Ilustrado" 31 de conteúdo bastante variado.

No período no qual ela circulou, a Revista Americana foi uma das mais importantes publicações que apareceram na cena cultural brasileira. Além de divulgar ideias, seu principal objetivo era "aproximar intelectuais, congregar espiritos, revelar identidades e promover formas de integração cultural entre os diversos povos da América”. Ao longo dos seus dez anos de vida, foram tratados os mais variados assuntos, com temas que versavam desde a diplomacia, propriamente dita, à crítica literária passando pela publicação de poesias e contos que, na maioria das vezes, tratavam de problemáticas sul-americanas.

Ao se analisar a Revista Americana fica explicito que um de seus principais objetivos foi estabelecer estratégias de "aproximação entre as Américas". E essa questão, naquele momento histórico, remetia, conforme dito, ao debate acerca do americanismo. As páginas da Revista registram uma série de artigos que expressavam tal preocupação.

Nessa perspectiva, alguns autores ${ }^{32}$ tendem a colocar a Revista Americana como um instrumento de divulgação da política americanista do 
Itamaraty junto à intelectualidade de então. Entretanto, convém salientar que a Revista apresentou, igualmente, espaço para divergências, com textos que criticavam o monroísmo, compreendendo-o, por exemplo, como parte central na estratégia imperialista norte-americana. $\mathrm{O}$ debate se deu em vários números e, mesmo reconhecendo a maior incidência de artigos favoráveis a uma aproximação entre a América do Sul e os Estados Unidos, é importante ressaltar o espaço para opiniões contrárias, o que, por si só, demonstra uma tentativa de que a Revista fosse um fórum minimamente neutro e aberto para o pleno exercício intelectual.

A análise da Revista Americana permite observar estratégias da ação diplomática do período, à luz de uma determinada visão de mundo e articulada a um projeto cultural que buscava destacar e diferenciar o posicionamento da América do Sul no cenário mundial, valorizando a existência de uma dada moral sul-americana, que possibilitaria o estabelecimento de um continente pacífico e ordeiro, fato que o colocaria como um exemplo a ser seguido, assim como ressaltaria as qualidades da diplomacia continental.

Pensar essa nova situação foi uma das preocupações da política e da diplomacia brasileira e, de certa forma, sul-americana, sendo que tais preocupações estiveram presentes na Revista Americana. Houve, nas páginas da Revista, uma preocupação em se esclarecer o significado histórico do monroísmo desde as suas origens até sua aplicação prática em fins do século XIX e primeiros anos do século XX.

Araripe Jr., no artigo "A Doutrina Monroe”, publicado em duas partes (dez. 1909 e jan. 1910), estabelece uma análise histórica do processo de construção do monroísmo. Neste particular, o autor defendeu a tese de 
que, tão importante quanto a Doutrina Monroe, foi a "declaração" de Polk, de 1845, que seria, para ele, o "reflexo do sentimento democrático americano" em oposição ao "espírito pérfido e perigoso da Santa Aliança", interessando na atitude de Polk "a força da corrente que irrompe através de todas as dificuldades políticas, quaisquer que elas fossem naquela hora", 33

Pode-se afirmar que, para Araripe Jr., a Doutrina Monroe seria fruto de um "sentimento americano", da própria vida nacional, sendo seu fortalecimento devido às repetidas tentativas de desagregação "por influência estrangeira, do sistema político em que se firmava a América". ${ }^{34}$ Logo, ela era vista como uma forma de defesa da paz e da estabilidade da América, evitando-se, por exemplo, a "africanização"35 do continente.

Seguindo essa lógica de valorização do monroísmo, Araripe Jr. teceu séria crítica a Eduardo Prado por sua obra A Ilusão Americana, de 1893. Nesta obra, Prado analisa o papel dos Estados Unidos nos processos de independência das colônias ibéricas na América, observando, entre outras temáticas, a posição estadunidense diante das investidas de governos europeus aos recém-formados países, assim como a sua influência política, moral e econômica sobre os mesmos. Segundo Prado, a política interna e externa dos Estados Unidos, à época subordinada à escravidão, não se orientaria a "fazer suas as brigas da América Latina com as potências europeias" e tal posição não teria mudado, desde então. Para o autor, residia nos ingleses - e não nos americanos do Norte - a "força moral" que propiciou a independência da América Ibérica.

São inegáveis, na análise dos artigos publicados na Revista Americana, as críticas, diretas ou indiretas, feitas à obra de Eduardo Prado. 
Dunshee de Abranches no artigo "O Brasil perante a Doutrina de Monroe" afirma que Prado era um "jovem e ardoroso monarquista", com o claro intuito de "impopularizar os primeiros governos republicanos", valendo-se, para isso, da argumentação de "publicistas europeus infensos ao povo norte-americano, [e que] o têm acusado de desvirtuamento da Doutrina de Monroe". ${ }^{36}$

Em seu artigo, Abranches, ao apresentar a temática do imperialismo, critica veementemente autores europeus, em especial J. Ribet, por suas posições anti-monroístas. Argumenta o autor que os políticos do "Velho Mundo" analisam a ameaça americana, no contexto da corrida imperialista, a partir da lógica de que a Doutrina de Monroe seria a causa, a justificativa, a explicação para o imperialismo norteamericano, sendo que este, para os europeus, teria tanto um aspecto político e moral, quanto - e sobretudo - um objetivo econômico. Citando Ribet:

A Doutrina de Monroe não é, em sua letra, um capricho, como não é uma virtualidade fácil: toda uma orientação econômica existe nela.[...] É a arma dos norte-americanos contra a Europa, arma que a Europa não volta contra eles, de modo que podem, com segurança, estender o seu poderio sobre a América inteira e o Universo. Sem a Doutrina de Monroe, o pan-americanismo e o imperialismo yankee não existiriam; eles são seus filhos. ${ }^{37}$

Segundo Abranches, essa visão europeia é explicável pela luta entre os mercados dos dois continentes, fato que fazia a Europa tomar precauções contra quaisquer tipos de ameaça, principalmente naqueles anos anteriores à Primeira Guerra Mundial. Nas palavras do autor: 
Diante dos outros países ainda pouco manufatureiros da América e oriundos de diversa formação étnica, não deixa de ser um processo engenhoso manter sempre os Estados Unidos como uma ameaça perene à sua integridade territorial ou à sua autonomia política. Se o nervo das transações comerciais é o crédito e este repousa na confiança recíproca dos que as operam, nada mais natural do que as praças da Europa continuarem a enfeixar o monopólio da exportação para as nações em que o seu grande concorrente da América setentrional se mostra sempre sob as aparências alarmantes de um conquistador insaciável. ${ }^{38}$

Analisando os escritos de Dunshee de Abranches na Revista Americana, pode-se perceber que, para o autor, o imperialismo estadunidense não seria um desdobramento direto da doutrina Monroe, mas sim "o resultado das ideias em voga entre as grandes potências do mundo contemporâneo", sendo posterior ao europeu e tendo surgido de uma necessidade conjuntural, diante da ação expansionista associada à "uma atitude agressiva, dilatando todos os seus domínios e apossando-se, aqui e ali, nos oceanos, de territórios importantes, quer pela sua posição estratégica, quer como empórios comerciais de primeira ordem". ${ }^{39}$

Igualmente, apesar de se admitir a ação imperialista estadunidense, esta acabava sendo observada e, portanto, justificada, como uma reação ao imperialismo europeu. Em síntese, Abranches defende que o imperialismo dos Estados Unidos se constituiu em uma arma de defesa em relação à ação imperialista européia, assim como argumenta que deveria haver um “equilíbrio continental", cabendo o domínio do Oceano Pacífico aos norte-americanos. Com um otimismo bastante evidente, defende a tese de que os Estados Unidos teriam a necessidade, "a quase obrigação" de intervir em determinadas questões internacionais como nos exemplos, 
citados pelo autor, dos arquipélagos do Havaí e de Samoa, uma vez que estes eram, naquele momento, assediados de todas as partes pelo "apetite colonizador de certas nações européias". Logo, os estadunidenses "não o fizeram impelidos pelo espírito imperialista do povo”, mas, sim, pelo próprio "instinto de conservação" que os levou a esses extremos "depois de larga relutância". Em resumo, para Abranches "o imperialismo yankee, proclamado do dia para a noite, devia ter, assim, profundamente irritado os governos autocráticos de além-mar, caracterizando-se, portanto, para o autor como uma arma de defesa contra o imperialismo europeu". ${ }^{40}$

Já no primeiro número da Revista Americana, Hélio Lobo, no artigo “George Canning ou James Monroe?”, ${ }^{41}$ defendeu, após análise dos antecedentes históricos da Declaração de Monroe, que o monroísmo deveria ser compreendido como uma "ideologia americana”, por "iniciativa americana" e em "função dos interesses americanos", bem como que os princípios expressos na declaração, ao serem consolidados, serviram de base para o desenvolvimento, ao longo do século XIX e início do XX, dos princípios do pan-americanismo.

Dentro dessa perspectiva de defesa do monroísmo nas páginas da Revista Americana, dois artigos de Joaquim Nabuco devem ser mencionados: "A parte da América na Civilização"42 e "A aproximação das duas Américas", ${ }^{43}$ respectivamente, no primeiro e terceiro números da Revista.

Originalmente uma conferência realizada nos Estados Unidos, "A parte da América na Civilização" abre o número inaugural da Revista. Ao falar da América, o próprio Nabuco admite estar se referindo apenas aos Estados Unidos, pois, segundo ele, era "cedo ainda para discorrer sobre a 
parte reservada na História à América Latina". ${ }^{44} \mathrm{O}$ autor chega a afirmar que "a América, graças à doutrina Monroe, é o Continente da Paz" e que "paz e pan-americanismo são termos equivalentes para vós e para nós". Evidentemente, o pan-americanismo é tomado como um mero desdobramento do monroísmo e, este, visto como uma doutrina de defesa continental contra agressões européias.

Vários outros colaboradores da Revista Americana se aproximaram dessa perspectiva de defesa do monroísmo, como Pedro Irigoyen, no artigo "Mediación e intervención", por exemplo, no qual defende a tese de que a Doutrina Monroe é um exemplo de solidariedade americana. Em suas palavras:

Desde que os Estados Unidos proclamaram, no ano 23 [1823], sua célebre doutrina de política continental, na qual, negando o direito de intervenção européia sobre os países sul-americanos, se arrojaram a faculdade de exercer um generoso e nobre protetorado sobre esses povos, não têm deixado de mediar em todas as questões transcendentais que a eles se refiram, procurando sempre garantir a vida dessas nacionalidades e estabelecer entre elas vínculos de verdadeira solidariedade. ${ }^{45}$

Conforme dito acima, o periódico abria espaço para opiniões divergentes. Um dos principais colaboradores da Revista Americana a estabelecer uma severa crítica ao monroísmo foi o argentino Norberto Piñero. No artigo "La Política Internacional Argentina", ao analisar a questão do reconhecimento da independência dos países sul-americanos, destaca a relevância do posicionamento inglês, sintetizado na atuação de Canning, que teria tido papel decisivo nesse processo, muito mais significativo do que os de Monroe e Adams. Piñero chama a atenção para 
o fato da diplomacia britânica apresentar como pilar central e "de uma maneira brilhante, a ação de Canning". Para o autor, o diplomata britânico configurou-se em poderoso homem de estado, tanto por seus atos quanto por suas palavras, sendo peça-chave no processo que culminou com o reconhecimento das independências. ${ }^{46}$

Para Piñero, a política continental norte-americana pautava-se pela garantia pragmática de seus interesses comerciais e pela prioridade de seus interesses internos em relação à solidariedade com outras nações. Ao analisar a Doutrina Monroe, afirmou que esta havia sido interpretada de diferentes maneiras, mas, em sua opinião, a única das interpretações interessante era:

[...]a de que ela não somente excluía às potências européias toda aquisição possível de territórios no Novo Mundo, mas trazia implícita a extensão da soberania dos Estados Unidos, no futuro, a todos os países do continente [...] pela suspeita e pelo temor de que a riqueza e a excepcional expansão conduzissem aquele grande povo a estabelecer seu poderio sobre os Estados independentes do sul [...]. ${ }^{47}$

Outro crítico à posição dominante, na Revista Americana, foi o chileno Marcial Martinez. No artigo “Cuestión Chileno-Peruana” (1911), defendeu que:

[...] fora de dúvida que os Estados Unidos aspiram à hegemonia sobre todo o novo continente. O sr. Blaine foi o fundador da idéia e seus colaboradores posteriores foram os senhores Root e Knox. A pretendida Doutrina Monroe não é outra coisa senão a proclamação implícita da hegemonia norte-americana ou simplesmente americana, como eles dizem, para manifestar que a América está representada pelos Estados Unidos. ${ }^{48}$ 
Martinez afirma que, para o povo chileno, o secretário de Estado Blaine era considerado o grande inimigo da nação, em decorrência dos atritos relativos à prisão de Garcia Calderón (presidente peruano reconhecido pelos Estados Unidos, mas não pelo Chile) após a Guerra Chileno-Peruana. Em síntese, Blaine era visto como o "iniciador do imperialismo dos Estados Unidos".

Também seguindo essa linha de abordagem, há o artigo "La intervención armada de los Estados Unidos en la República Dominicana”, de Jacintho López, que afirma ser o controle dos norte-americanos sobre as alfândegas, bem como sobre a dívida externa dominicana, um primeiro passo para o controle tanto da renda interior quanto das vias de comunicação do país, com o ministro norte-americano intervindo na política, na legislação, no governo, em suma, em todas as questões públicas. Ou seja, para López, as intervenções deixavam antever uma clara perspectiva imperialista de usurpação de todas as riquezas da república. ${ }^{49}$

Com essa mesma linha de argumentação, Vicente Gay, ao analisar a abertura do Canal do Panamá, no artigo "El Canal del Panamá y la crisis económica intercontinental", Gay criticava duramente a Doutrina Monroe, como podemos observar nessa passagem de seu texto:

[...] houve um tempo em que a Doutrina de Monroe significava a fórmula da indpendência americana: a Europa não podia seguir nenhum intento colonizador no continente americano; a era da colonização ativa havia terminado e começava a colonização dos territórios americanos sob a soberania dos próprios Estados da América. Mas, hoje que a avalanche de gentes da América do Norte e da Ásia constitui um sério perigo para os americanos filhos do tronco latino, a exclusão que proclama a Doutrina de Monroe 
significa o monopólio da América pelos norteamericanos e a falta de defesa contra asiáticos, ao mesmo tempo em que o afastamento dos povos europeus, que podem proporcionar os melhores elementos de resistência, que são os núcleos de população. ${ }^{50}$

Essa análise das diferentes formas de se pensar o binômio monroísmo/americanismo foi uma preocupação no periódico, apresentando um posicionamento voltado para a observação da necessidade histórica de um americanismo, pensado como elemento fundamental para a paz do continente americano. Penso a Revista Americana inserindo-a nessa lógica de aproximação das nações sulamericanas em busca da construção de uma estratégia diplomática voltada para o equilíbrio do continente, garantidora da paz, em um contexto de enorme instabilidade com um mundo sofrendo com as conseqüências da Corrida Imperialista que levaria as nações centrais para uma guerra generalizada e uma América, especialmente do Sul, buscando se inserir nesse cenário, tentando consolidar suas instituições.

\section{Considerações finais}

Em face do exposto, considero de extrema relevância, inserir a Revista de Derecho, Historia y Letras e a Revista Americana no debate intelectual e diplomático sul-americano, do período, reconhecendo a contemporaneidade das preocupações que as inspiraram e do espírito pioneiro que as orientaram na formulação de um novo vocabulário político com o debate de uma série de questões que marcavam a época, 
bem como a importância dos periódicos nos projetos políticos de Argentina e Brasil, respectivamente, no que tange os seus objetivos de consolidarem determinados projetos de identidade nacional/continental.

Em síntese, a criação dos periódicos fez parte de uma estratégia política e intelectual defendida tanto por Zeballos quanto por Rio Branco que consistiria em colocar a Argentina e Brasil na condição de exemplo para a América do Sul e, portanto, como líderes no projeto de se estabelecer um intercâmbio entre as nações do continente. Convém salientar a relevância de se pensar os periódicos tanto para compreender aspectos da História intelectual sul-americana quanto para se estabelecer reflexões acerca das relações internacionais no continente em um momento de extrema tensão.

Há que se ter em mente que, no alvorecer do século $\mathrm{XX}$, a diplomacia caracterizou-se como um instrumento de civilização regulador das relações internacionais servindo como instituição responsável pela defesa das nações menos poderosas, passando por elemento estratégico de expansão comercial e negociadora em situações extremas de conflito armado, promovidas, fundamentalmente, pelas nações centrais da economia capitalista.

Nos debates presentes nas revistas ficava latente a necessidade de se pensar um determinado projeto para a América do Sul em um contexto de evidente tensão entre uma ordem internacional, ainda vigente, baseada no princípio "hobbesiano-vestfaliano" e a gênese de um novo sistema internacional que só viria a se consolidar após 1945, com a "era da política mundial". ${ }^{1}$ Uma época, portanto, de transição, de crise de valores e de paradigmas, que trazia consigo um enorme desafio para aquela geração 
intelectual: o de compreender um mundo em constante mudança sem referências consolidadas.

Um dos pontos centrais das publicações foi indicar caminhos para a América do Sul que deveriam ser trilhados nas décadas seguintes. Neste sentido, analisar as diferentes concepções acerca do americanismo é fundamental, na medida em que os intelectuais que colaboravam nos periódicos apresentaram, ao refletirem acerca do conceito, um conjunto de idéias norteadoras que continuaram ao longo das décadas seguintes a serem discutidas e aplicadas em outros projetos intelectuais, principalmente no que tange a busca de uma integração continental, buscando responder questões como: o que seriam as Américas no contexto da cultura ocidental? Quais seriam as aproximações possíveis entre elas assim como seus distanciamentos? Qual era a identidade ou as identidades americanas? Qual deveria ser o futuro do continente?

\section{Notas}

*Professor Associado de História da América do Instituto de História da Universidade Federal do Rio de Janeiro e do Programa de Pós-Graduação em História Social (PPGHIS-UFRJ); Programa de Pós-Graduação em História Comparada (PPGHC-UFRJ) e do Mestrado Profissional em Ensino de História (Prof. Hist. - UFRJ). ORCID: 00000001-7495-2707.

${ }^{1}$ Ver: SKINNER, Q. Meaning and Understanding in the History of Ideas. In: TULY, J. Meaning and Context: Quentin Skinnerand his Critics. Princeton: Princeton University Press, 1988. POCOCK, J. G. Linguagens do ideário político. São Paulo, EDUSP, 2003.

2 POCOCK, J. G. Linguagens do ideário político. op cit. A perspectiva do lance remete, segundo Pocock, a um processo no qual um ato de fala é enunciado e de certa forma busca inovar o contexto linguístico, permitindo ao historiador observar o que um autor (ou grupo de autores) estava fazendo no momento de elaboração de seu discurso.

3 CRESPO, R. Introducción. In: CRESPO, R. (coord). Revistas en América Latina: proyectos literarios, políticos y culturales. Cidade do México, UNAM, 2010.

4 Ibid., p. 9. 
${ }^{5}$ HOBSBAWM, E. A Era dos Impérios. Rio de Janeiro, Paz e Terra, 1988.

6 Sobre isso ver entre outros: HALE, C. Ideias políticas e sócias na América Latina1870-1930. In: BETHELL, L. (org) História da América Latina. Vol. 4. São Paulo: EDUSP, 2004.

${ }^{7}$ Estou considerando geração, defendendo a tese na qual a compreensão deste conceito perpassa pela fusão de memória e história, ou seja, da existência de uma "memória comum", um testemunho de como um conjunto de homens viveu certo tempo. Sobre isso ver: ATTIAS-DONFUT, C. La Notion de Generation: usage sociaux et concept sociologique In: L' Homme et la Societé. Paris: L' Harmattan (90), 1988. SIRINELLI, J-F. Le_Genération: la construction du temps historique. Paris: Histoire au Present, 1991.

8 ROMERO, L. A. História Contemporânea da Argentina. Rio de Janeiro: Jorge Zahar, 2006.

9 ROCK, D. La construcción del Estado y los movimientos políticos em la Argentina, 1860 - 1916. Buenos Aires: Prometeo Libros, 2006; OSZLAK, O. La formación del Estado argentino: ordem, progreso y organización nacional. Buenos Aires: Emecé Editorial, 2009; HALPERIN DONGHI, T. Proyecto y construcción de uma Nación. Buenos Aires: Emecé Editorial, 2007; ROMERO, J. L. Breve Historia de la Argentina. Buenos Aires: FCE, 1997.

10 PARADISO, J. Um lugar no mundo: a Argentina e a busca de uma identidade nacional. Rio de Janeiro: Civilização Brasileira, 2005.

11 Esta pode ser vista em: SEVCENKO, N. Literatura como Missão. São Paulo, Brasiliense, 1995; HERSCHMANN, M. A Invenção do Brasil Moderno. Rio de Janeiro: Rocco, 1995; VENTURA, R. Estilo Tropical. São Paulo: Cia das Letras, 1991; SCHWARCZ, L. O espetáculo das Raças. São Paulo: Cia. das Letras, 1992; MARTINS, W. História da Inteligência Brasileira. São Paulo: Editora Civilização Brasileira, 1966. HARDMAN, F. F. O trem fantasma: a modernidade na selva. São Paulo: Cia das Letras, 1991.

12 BELloto, M. L. \& CORRÊA, A. M. M. (orgs.) Bolívar, Simón: Política. Rio de Janeiro: Ed. Ática, 1983.

13 SANTOS, L. C. V. O Brasil entre a América e a Europa: o Império e o interamericanismo (do Congresso do Panamá à Conferência de Washington). São Paulo: UNESP, 2004.

14 Ver: ATKINS, P. G. A América Latina em el sistema político internacional. Buenos Aires, Grupo Editor Latinoamericano, 1991; CAMPOS, C. Estados Unidos América Latina y el caribe: entre el panamericanismo hegemónico e la integración independente. In: História y Perspectiva de la integración Latinoamericana. Morelia, Universidad Michoacana San Nicolás de Hidalgo, México, 2000; GLINKIN, A. El latinoamericanismo contra el Panamericanismo desde Simón Bolívar hasta nuestros dias. Moscou: Progresso, 1984.

15 BUENO, C. Do Idealismo ao Realismo: Brasil e Cone Sul no início da República (1889 - 1902). Contexto Internacional, $n^{\circ}$ 12, Rio de Janeiro, IRI/PUC, pp. 71-82, 1990.

16 Sobre isso, ver, entre outros: BARROS, M. Historia Diplomática de Chile (15411938). Barcelona, Ediciones Ariel, 1979. 
${ }^{17}$ Considerado, por muitos, uma das figuras mais importantes da cena política e cultural da Argentina de fins do século XIX e início do XX. Além de editor, Zeballos foi o maior articulista do periódico.

18 ZEBALLOS, E. S. Revista de Derecho, Historia y Letras. Buenos Aires, J. Peuser, n 1 , pp. $5-7$.

${ }^{19}$ SÁNCHEZ, A. Solidaridad Latino-americana. Problemas externos e internos. Revista de Derecho, Historia y Letras t. XXIV, pp. 147-157, 1906.

${ }^{20}$ Ibid., p. 151.

${ }^{21}$ Ibid., p. 156.

22 SUBERCASSEAUX, V. B. El Congreso Pan-Americano de Río. Revista de Derecho, Historia y Letras. t. XXIV, pp. 392-400, 1906.

${ }^{23}$ ROOT, E. El verdadero objeto de la unidad Pan-americana. Revista de Derecho, Historia y Letras t. XXV, pp. 71-72, 1906.

${ }^{24}$ Ibid., p. 72.

25 Oficina Internacional de las Repúblicas Americanas: Importancia de la Conferencia Panamericana de Río de Janeiro. In: Revista de Derecho, Historia y Letras., t. XXV, pp. 98-113, 1906.

${ }^{26}$ Ibid,. p. 75.

27 Senado Federal. Revista Americana: uma iniciativa pioneira de cooperação intelectual. Seleção de artigos fac - similar. Brasília, FUNAG, 2001. Apresentação.

${ }^{28}$ Editorial. Revista Americana. vol. 1, setembro, 1909, p. 2.

29 Chanceler brasileiro entre 1902 e 1912. Considerado o principal responsável pela modernização da diplomacia no Brasil.

${ }^{30}$ Idem.

$31 \mathrm{O}$ suplemento restringiu-se a esses quatro números.

32 Ver: BAGGiO, K. A Revista Americana e as relações entre as Américas. Belo Horizonte: FAFICH/UFMG, s.d. Mimeografado.

33 ARARIPE, Jr. A Doutrina Monroe. Revista Americana. vol. 1, no 3, dezembro, 1909. p. 67.

34 Ibid., p. 77.

35 No sentido de 'partilha', ação ocorrida na Conferência de Berlim de 1885.

36 ABRANCHES, D. de. O Brasil perante a Doutrina Monroe. Revista Americana. vol. 2, no 2, fevereiro, 1910. p. 181.

37 Ibid., p. 184.

38 Ibid., pp. 182-183.

39 Ibid., p. 186.

${ }^{40}$ Ibid., pp. 189-190.

${ }^{41}$ LOBO, H. George Canning ou James Monroe? Revista Americana. vol. 1, no 1 , setembro, 1909.

42 NABUCO, J. A parte da América na Civilização. Revista Americana. vol. 1, no 1 , setembro, 1909.

${ }^{43}$ NABUCO, J. A aproximação das duas Américas. Revista Americana. vol. 3 no 2, maio, 1910.

${ }^{44}$ NABUCO, J. op cit., 1909, p. 16. 
45 IRIGOYEN, P. Mediación e intervención. Revista Americana. vol. 6 nº 2, maio, 1911, p. 318.

46 PIÑERO, N. La Política Internacional Argentina. Revista Americana. vol. 9, $\mathrm{n}^{\circ}$ 1, janeiro, 1913, pp. 60-61.

47 PIÑERO, N. La Política Internacional Argentina. Revista Americana. vol. 9, $\mathrm{n}^{\circ}$ 2, fevereiro, 1913, p. 174.

48 MARTINEZ, M. Cuestión Chileno-Peruana. Revista Americana. vol. 6 no 2, maio, 1911, p. 110.

49 LÓPEZ, J. La intervención armada de los Estados Unidos en la República Dominicana. Revista Americana. vol. 6 n 2, maio, 1911.

50 GAY, V. El Canal del Panamá y la crisis económica intercontinental. Revista Americana. vol. 9, n 3, março, 1913, p. 323.

${ }^{51}$ Ver: BARRACLOUGH, G. Introdução à História Contemporânea. Rio de Janeiro: Ed Zahar, 1976; GONÇALVES, W. Relações Internacionais. Rio de Janeiro: Jorge Zahar Editor, 2002. 